Eilosofia moderna

revista de e contemporânea

Intencionalidade e consciência em Searle

Joelma Marques de Carvalho Professora da Universidade Federal do

Ceará

Resumo: O objetivo deste artigo é apresentar uma análise crítica sobre a relação entre intencionalidade e consciência em John Searle. Conforme este autor, estes fenômenos são intimamente relacionados entre si, mas os conceitos de intencionalidade e consciência não são equivalentes e nenhum deles abrange completamente o outro, pois a preposição "de" em expressões da intencionalidade não significa o mesmo que a preposição "de" nas expressões da consciência. No entanto, através de uma análise mais profunda da teoria searleana da mente, especialmente acerca do estatuto ontológico dos conteúdos dos estados inconscientes, é possível perceber que a separação entre intencionalidade e consciência defendida por Searle é questionável.

Palavras-chave: Searle, intencionalidade, consciência, inconsciente, pano de fundo, estatuto ontológico.

\section{Intentionality and Consciousness by}

Searle

\begin{abstract}
The objective of this article is to present a critical analysis about the relation between intentionality and consciousness in John Searle. According to this author, these phenomena are closely related to each other, but the concepts of intentionality and consciousness are not equivalent and neither of them comprises the other completely, for the preposition "of" in expressions with intentionality does not mean the same as the preposition "of" in expressions with consciousness. However, by means of a deeper analysis of Searle's theory of mind, especially about the ontological status of the content of unconscious states, it is possible to see that the separation between intentionality and consciousness defended by Searle is questionable.
\end{abstract}

Keywords: Searle, intentionality, consciousness, unconsciousness, backeground, ontological status. 


\section{Introdução}

O objetivo principal deste trabalho é tratar a relação entre intencionalidade e consciência na teoria da mente de John Searle $\left(1932^{*}\right)$ e apresentar algumas das dificuldades que esta teoria enfrenta. Para uma melhor compreensão desta análise, iremos apresentar primeiramente suas noções de intencionalidade, consciência, autoconsciência, inconsciente, pano de fundo ou background, rede e memória. Depois, iremos avaliar como estes fenômenos estão relacionados entre si. Por último, veremos que em sua tentativa de lidar com o problema do estatuto ontológico dos conteúdos proposicionais de estados mentais inconscientes, ele acaba tendo que modificar algumas destas concepções e tornando sua teoria da mente incoerente na medida em que embora aceite a íntima relação existente entre intencionalidade e consciência, ele parece continuar defendendo a tese de que nem todos os estados intencionais são conscientes (SEARLE, 1992: 125).

\section{Intencionalidade}

Searle define intencionalidade como a capacidade que muitos estados e eventos mentais possuem de serem dirigidos para ou acerca de algo no mundo (SEARLE, 1983:1). Em outras palavras: INTENCIONALIDADE é direcionalidade. Por exemplo, se um indivíduo A deseja ganhar na loteria, então o seu desejo é acerca do estado de coisas de ganhar na loteria. Observe que o objeto ou estado de coisas, ao qual estado intencional se refere não precisa existir no mundo. Isto nos mostra que a intencionalidade não é uma relação comum como, por exemplo, estar sentado sobre uma cadeira.

Em sua teoria da mente, Searle distingue os seguintes tipos de intencionalidade, a saber: (a) intrinseca, (b) derivada, (c) individual e (d) coletiva. A intencionalidade intrínseca (a) é a intencionalidade apenas de estados mentais que existe independentemente de qualquer observador. Neste contexto, Searle utiliza o termo "intrínseco" em oposição a "aparente". Isto significa que os estados intencionais são simplesmente fatos reais (SEARLE, 1997: 94). A intencionalidade derivada (b) é a intencionalidade do significado linguístico dos atos de fala, a qual depende dos observadores e usuários da linguagem. Conforme este autor, esta forma de intencionalidade deriva da intencionalidade da mente. A intencionalidade individual (c) é a intencionalidade do eu que possui a forma na primeira pessoa do singular tais como "eu tenho a intenção de", "eu acredito que" etc. Por último, a intencionalidade coletiva (d) é a intencionalidade do eu que possui a forma na primeira pessoa do plural tais como "nós temos a intenção", "nós acreditamos" etc. Este tipo de intencionalidade não é redutível nem à intencionalidade individual nem à crença mútua, pois não se trata da soma de intencionalidades individuais. Além disso, a intencionalidade coletiva é a base para todas as atividades sociais tais como jogos de futebol, missa, sala de aula, palestras etc.

Vale ressaltar que esses tipos de intencionalidade não devem ser confundidos com a intencionalidade "como se", ou seja, com a intencionalidade em um sentido metafórico. Por exemplo, se afirmamos que as plantas sentem sede ou que têm fome de nutrientes porque estão murchando, isto não implica em outro modo de intencionalidade, mas 
apenas em um modo de descrição intencional em um sentido apenas metafórico. Deste modo, para Searle, somente estados mentais e significado linguístico possuem alguma forma de intencionalidade.

\section{Estrutura lógica dos estados intencionais}

O modo que Searle utiliza para explicar o fenômeno da intencionalidade é descrevendo a estrutura lógica dos estados e eventos intencionais sem a qual não poderíamos entender a vida consciente. Neste âmbito, ele afirma que esta explicação dos estados intencionais não se trata de uma discussão fenomenológica dos mesmos. De acordo com esta análise, nós temos as seguintes distinções abaixo:

(i) Distinção entre tipo (força ilocucionária) e conteúdo - a cada estado mental é possível fazer uma diferenciação entre tipo e conteúdo. Por exemplo: Um indivíduo $\mathrm{x}$ deseja saltar de paraquedas e um indivíduo y tem medo de saltar de paraquedas. Neste caso, os indivíduos $\mathrm{x}$ e $\mathrm{y}$ possuem estados intencionais de tipo diferentes, a saber, o desejo e o medo, mas ambos têm o mesmo conteúdo intencional, saltar de paraquedas. Isto não significa que o conteúdo intencional é sempre uma proposição completa, pois em casos de alguns estados intencionais tais como o ódio ou o amor, o conteúdo intencional pode ser apenas um objeto.

(ii) Direção de ajuste [directions of fit] os estados intencionais possuem uma direção de ajuste tais como os atos de fala. Se um indivíduo $\mathrm{x}$ acredita que amanhã irá chover, a sua crença tem a direção de ajuste mente-mundo. Neste caso, se o ajuste falha é possível mudar a crença e ela deixará de ser falsa. No entanto, se o indivíduo x deseja que amanhã não chova, então a direção de ajuste deste estado intencional é mundomente, pois para que o estado mental seja satisfeito é necessário que os estados de coisas do mundo se comportem como foi desejado pelo indivíduo.

(iii) Condições de satisfação [conditions of satisfaction] - as condições de satisfação são internas aos estados intencionais. Elas aparecem quando os estados intencionais possuem uma proposição completa como conteúdo intencional e uma direção de ajuste. Se alguém acredita que amanhã não choverá, então a condição de satisfação deste estado intencional é que não chova.

(iv) Modo ou aspecto psicológico [psychological mode] - os estados intencionais representam as suas condições de satisfação, isto é, os objetos e estados de coisas do mundo através de certos aspectos que são fundamentais para o sujeito. Por exemplo: Um indivíduo x deseja beber água. A condição de satisfação deste desejo poderá ser simplesmente beber água e não $\mathrm{H}^{2} \mathrm{O}$.

Estas características da estrutura lógica dos estados intencionais nos mostra que $\mathrm{O}$ modelo da intencionalidade é muito semelhante ao modelo da linguagem. Isto significa que os estados intencionais representam os objetos e estados de coisas do mundo de modo análogo aos atos de fala. Contudo, por "representação" não se entende aqui uma apresentação de um objeto, o qual foi experenciado anteriormente pela 
consciência e nem uma imagem mental subjetiva de um indivíduo. Além disso, segundo este autor, as representações não devem ser compreendidas em um sentido ontológico. O conceito de representação é definido como o conjunto de características lógicas dos estados intencionais (SEARLE, 1983: 22). Sendo assim, afirmar que os estados intencionais representam algo significa dizer que eles possuem um conteúdo proposicional com uma direção de ajuste, o qual determina condições de satisfações sob um modo ou aspecto psicológico.

\section{Rede (Network) e Pano de fundo (Background)}

Searle defende que os estados intencionais não determinam as suas condições de satisfação isoladamente, mas apenas a partir de uma rede de outros estados intencionais. Além disso, o funcionamento dos estados e eventos intencionais exige as capacidades do background. Por "background" entende-se o conjunto de capacidades e habilidades mentais não representacionais que um indivíduo possui (SEARLE, 1983: 143). Ele envolve determinados tipos de conbecimento prático [know-how], os quais são condições necessárias, mas não suficientes, para a própria existência dos estados intencionais.

Neste âmbito, Searle faz uma distinção entre background profundo e background local. O background profundo envolve as capacidades comuns a todos os seres humanos normais em virtude de sua constituição biológica tais como andar, comer, reconhecer etc. Já o background local inclui as capacidades que adquirimos através de práticas culturais locais, como por exemplo, beber cervejas em garrafas, abrir portas etc. Este autor assume que não possui provas da existência do background, mas afirma que chegou a esta noção através de suas pesquisas sobre a compreensão do significado linguístico, a aquisição de capacidades físicas tais como esquiar e a interpretação dos estados intencionais, as quais exigem as capacidades do background.

Em sua obra Intentionality (1983), a distinção entre rede e background não é tão clara, mas a partir de seu livro The Rediscovery of the Mind (1992), ele afirma que a rede faz parte do background. No entanto, não é possível estabelecer a rede holística que um indivíduo possui ao ter um estado intencional como, por exemplo, uma intenção de se candidatar à presidência de um país. Os motivos principais são:

(a) A maior parte da rede está submersa no inconsciente e não se sabe como trazê-lo à consciência;

(b) Os estados intencionais que constituem a rede não se individualizam;

(c) Nós tenderíamos à formulação de proposições duvidosas ou de um conjunto de crenças inconscientes que provavelmente não combinariam com outras crenças que temos. Por exemplo: Quando um indivíduo se senta em uma cadeira, ele não formula no momento atual uma crença inconsciente de que a cadeira é sólida, mas ele se comporta como se a cadeira fosse sólida. Isto significa que o sujeito não pensa a respeito da solidez da mesa, ele simplesmente age.

\section{Causação intencional}

Para Searle, os estados mentais estão em uma relação causal com o mundo e vice-versa, a qual possui uma autorreferencialidade. Por exemplo: Se um indivíduo deseja levantar o seu braço direito, então faz parte 
das condições de satisfação desta intenção que: (i) este indivíduo levante o braço direito e que (ii) a sua intenção de levantar o braço faça com que o seu braço direito se movimente para cima. Deste modo, a causalidade intencional envolve tanto um componente causal quanto um componente intencional. Além disso, esta noção de causalidade é mais ampla do que a causalidade da bola de bilhar e nós experenciamos a causação intencional de forma direta.

No entanto, na teoria searleana da mente, existem dois tipos de causação intencional: (a) a causação em seu microcosmo e (b) a causação em seu macrocosmo. A primeira forma de causação trata-se do nível de neurônios individuais e a segunda no nível dos estados mentais que surgem como propriedades emergentes do conjunto de neurônios individuais. Deste modo, os estados intencionais, como por exemplo, a intenção de levantar o braço, pode ser descrita tanto em seu nível micro quanto em seu nível macro de modo análogo à solidez da mesa, visto que a solidez é uma propriedade emergente da mesa, mas em seu microcosmo, ela não é o resultado do comportamento de suas moléculas individuais. A diferença entre estas duas descrições é que a característica da solidez da mesa pode ser reduzida ontologicamente à sua base física. Já os estados mentais conscientes, podem ser reduzidos de forma causal à sua base neurobiológica em seu microcosmo, mas esta redução causal não nos leva a uma redução ontológica dos mesmos (SEARLE, 1992: 116).

A aceitação da redução causal e a recusa da não redução ontológica dos estados mentais feitas por Searle é atualmente muito criticada na filosofia contemporânea da mente e ainda está em debate. Em resposta aos críticos desta posição, ele continua apenas defendendo que os principais motivos para a não redutibilidade dos estados mentais no sentido ontológico (e não epistêmico) são:

(i) Em seu nivel macrocosmo, os estados mentais são propriedades emergentes do cérebro e possuem a característica da subjetividade on ontologia de primeira pessoa, isto é, eles só existem na medida em que bá alguém que os experencie e esta propriedade não pode ser considerada a partir de uma ontologia de terceira pessoa.

(ii) Parte do objetivo de uma redução ontológica é estabelecer a distinção entre aparência e realidade, mas esta distinção não pode ser aplicada à mente da mesma forma que os objetos que possuem uma ontologia de terceira pessoa. (SEARLE, 1992: 121-122)

\section{Consciência}

Searle não fornece uma definição do conceito de consciência, uma vez que em sua opinião o termo "consciência" não pode ser definido de uma forma que não seja circular. Para explicar a noção de consciência, ele apresenta apenas alguns exemplos e descreve algumas características. Em sua visão, um indivíduo está consciente quando ele acorda após ter dormido sem ter tido sonhos (SEARLE, 1992: 124).

Vale ressaltar que a consciência dos próprios estados mentais conscientes ou autoconsciência [self-consciousness] não implica uma reflexão sobre os estados mentais ou uma atenção do sujeito voltada para si mesmo. Em seu sentido técnico, a autoconsciência existe sempre que temos um estado mental. Se um indivíduo $\mathrm{x}$ percebe um determinado objeto y como, por exemplo, uma cadeira diante de si, não apenas a cadeira y será percebida pelo sujeito como também o próprio ato de ver 
ou a percepção visual em si. Por este motivo, a nossa consciência possui a capacidade de voltar o foco para a própria experiência visual ou para o objeto intencional. Naturalmente isto altera o caráter deste estado intencional consciente. No entanto, isto não significa que não havia um estado mental consciente da percepção visual.

Neste contexto, Searle critica a noção de introspecção enquanto uma espécie de observação interna dos próprios estados mentais, uma vez que nos casos dos próprios estados mentais conscientes não é possível fazer uma distinção entre o objeto percebido e estado mental que o percebe. Outro problema desta concepção é que ela utiliza uma falsa analogia da percepção dos próprios estados mentais com a percepção visual de objetos externos como, por exemplo, uma cadeira. Contudo, a introspecção só é possível enquanto uma espécie de avaliação dos próprios estados mentais. Tomemos o seguinte exemplo: Maria é pedida em casamento por João e resolve então avaliar os seus sentimentos por João para saber se ela realmente o ama ou não. Apenas em casos como este, a noção de introspecção faz sentido.

Além disso, como já foi dito anteriormente, este autor defende a ideia de que no âmbito da consciência a distinção entre aparência $e$ realidade não pode ser feita, pois estas duas coisas são indistinguíveis (SEARLE, 1992). Deste modo, nós não pressupomos a existência da consciência. Estados conscientes são fatos. Mesmo assim, isto não significa que nós não podemos estar errados acerca de nossos próprios estados mentais, visto que a consciência não traz necessariamente um conhecimento sobre os mesmos. Isto nos mostra que Searle não entende a consciência como cognição ou conhecimento.
As explanações feitas até o momento têm o propósito de oferecer uma visão geral sobre o que Searle entende por intencionalidade e consciência. Vejamos agora como este autor compreende a relação entre essas duas características fundamentais da mente.

\section{Intencionalidade e Consciência}

Searle defende que nem todos os estados intencionais são conscientes e que nem todos estados conscientes são intencionais (SEARLE, 1983: 2). Em sua opinião, estados psicológicos tais como nervosismo, exaltação, ansiedade, depressão e as dores podem ser conscientes e não serem intencionais, uma vez que às vezes não sabemos dizer a que objeto ou situação estes estados mentais se referem. Outros estados mentais como, por exemplo, os nossos pensamentos que não são atuais, são intencionais, mas não são conscientes. Deste modo, enquanto a noções de consciência e intencionalidade são, para Franz Brentano (1838-1917), inseparáveis ou até mesmo indistinguíveis, Searle defende a ideia de que estes conceitos não são idênticos e nenhum deles abrange $o$ outro, pois a preposição de em expressões acerca de estados conscientes não significa o mesmo que a preposição de em expressões acerca dos estados ou eventos intencionais.

Vejamos então alguns destes casos individualmente. Conforme este autor, no caso de algumas emoções, como por exemplo, a ansiedade, não é possível diferenciar a ansiedade em si da experiência da ansiedade. Já nos casos de estados intencionais, nós sabemos distinguir o estado mental de seu objeto intencional. Por este motivo, a ansiedade seria consciente, mas não intencional. Contudo, esta argumentação não é aceita tão facilmente na filosofia contemporânea. Neste contexto, o filósofo analítico Tim 
Crane (1962*), por exemplo, defende que a questão "para que se dirige um estado mental?" nem sempre é o melhor caminho para dizermos se um estado mental é intencional ou não, uma vez que o sujeito nem sempre tem autoridade epistêmica acerca de seus estados mentais (CRANE, 2006: 34). Observe também que nos casos de ansiedade, nervosismo ou alterações de humor nós não perguntamos geralmente acerca do objeto intencional deste estado mental, mas acerca de sua causa. No entanto, é possível que a causa de um estado mental seja o seu objeto intencional, mas isso não ocorre sempre. Tomemos como exemplo uma criança que tem medo de um cachorro ao encontrá-lo na rua. É possível que a causa deste medo possa estar em um passado distante, no presente ou até mesmo no futuro, e que ela desconheça a causa deste medo, mesmo assim nós não diríamos que o objeto intencional deste medo seria sua causa, mas sim o cachorro que ela viu na rua.

Com relação às dores, os filósofos Crane e Michael Tye $\left(1950^{*}\right)$ defendem que as experiências sensoriais e as dores são intencionais, pois estes estados mentais possuem uma representação sensorial que indicam algo ou apontam para algo. Deste modo, tanto Crane (CRANE, 2001) quanto Tye (TYE, 1996) assumem a explicação de Brentano (BRENTANO, 1874) de que as dores são intencionais, uma vez que é possível fazer a distinção entre a sensação da dor e a dor em si, a qual pode ser localizada em alguma parte do corpo. Por exemplo, as dores fantasmas, as quais são afirmadas acontecer por muitos pacientes depois de terem algum de seus membros amputado, apontariam para esta distinção. Neste caso, os pacientes possuem a sensação de dor, apesar de não possuir mais o membro amputado (ou parte dela), onde a dor possa ser localizada. Neste âmbito, o próprio Searle acaba aceitando esta exceção e afirma que neste caso a dor seria intencional, pois ela possui condições de satisfação e a própria possibilidade do sujeito cometer um erro já seria um bom indício de que o estado mental é intencional (SEARLE, 1992: 251). Porém, esta afirmação não parece ser coerente com sua tese inicial de que os estados mentais como os exemplos já citados não são intencionais, uma vez que às vezes não sabemos dizer a que objeto ou situação estes estados mentais se referem (SEARLE, 1983: 2).

Resta-nos agora analisar o outro lado da moeda, ou seja, os casos de pensamentos não atuais que, segundo este filósofo, seriam intencionais, mas não seriam conscientes. No entanto, para considerarmos estes casos de forma mais crítica, precisamos ter uma compreensão geral de sua concepção de inconsciente a seguir.

\section{Inconsciente}

Searle afirma que não há uma noção unificada de "inconsciente" e distingue quatro concepções de estados inconscientes, a saber:

(i) Os eventos não conscientes tais como a mielinização dos axônios do sistema nervoso central.

(ii) Os estados profundamente inconscientes, os quais são em princípio inacessíveis à consciência.

(iii) Os estados pré-conscientes como, por exemplo, pensamentos, desejos, preocupações e memórias não atuais.

(iv) Os estados inconscientes reprimidos devido a alguma experiência traumática.

O primeiro conceito de estados inconscientes abrange eventos que não seriam sequer mentais, pois estes não possuem uma 
intencionalidade intrínseca, mas apenas intencionalidade no sentido metafórico. Em sua teoria da mente, Searle defende que as principais características dos estados mentais são: (a) intencionalidade, (b) consciência, (c) subjetividade ou ontologia de primeira pessoa e (d) qualitatividade. A subjetividade ou ontologia de primeira pessoa se refere ao fato de que a sua existência depende da experiência do sujeito. A qualitatividade se refere ao modo como os estados mentais são experenciados pelo sujeito. Isto não significa que os estados mentais devem possuir todas estas características ao mesmo tempo, mas eles devem possuir pelo menos alguma destas propriedades. Como os eventos tais como a mielinização dos axônios não possuem nenhuma destas características, eles não são mentais apesar de ocorrerem no cérebro e serem necessários para a produção de estados mentais.

A segunda concepção de inconsciente se aproxima da noção de inconsciente em si de Sigmund Freud (1856-1939). De acordo com Searle, o problema deste conceito freudiano é que os estados inconscientes mantêm a mesma forma aspectual dos estados conscientes. Sendo assim, a distinção entre inconsciência e consciência é que a inconsciência não tem a consciência, mas ambos existem do mesmo modo. Além disso, eles seriam causalmente ativos. Por exemplo: a raiva inconsciente de uma criança acerca de seu pai pode causar um comportamento agressivo na escola. A existência deste tipo de estados inconscientes é postulada então para explicar o comportamento. Neste contexto, Searle compara os estados inconscientes no sentido freudiano a peixes no fundo mar, os quais estariam invisíveis ou inacessíveis à consciência, uma vez que os mesmos não têm o aspecto alterado quando eles emergem. Em sua opinião, esta definição de inconsciente enfrenta vários problemas, mas os dois principais problemas são: em primeiro lugar, ela viola o princípio lógico da intencionalidade que é ter sempre uma forma aspectual e não poderia assim ter a característica da subjetividade ou ontologia de primeira pessoa, visto que os estados inconscientes são intrinsecamente inconscientes e não podem ser experenciados pelo sujeito; em segundo lugar, esta definição pressupõe uma falsa analogia da consciência com a percepção, pois pressupõe que os estados mentais podem ser experenciados da mesma forma que os objetos e fatos do mundo. Isto significa que ela pressupõe a introspecção no sentido criticado por Searle, ou seja, uma observação interna dos próprios estados mentais.

Sendo assim, Searle rejeita as duas primeiras noções de inconsciente e utiliza o termo "inconsciente" apenas no terceiro e quarto casos, ou seja, como sinônimos de pré-conscientes ou estados mentais reprimidos. Disto se segue o seu princípio da conexão, ou seja, a tese de que todos os estados inconscientes devem ser potencialmente acessíveis à consciência (SEARLE, 1992: 160). Caso contrário, eles não seriam mentais.

O nosso propósito será agora fazer uma análise mais profunda da sua teoria da mente a partir da questão sobre o estatuto ontológico tanto dos estados conscientes quanto dos conteúdos dos estados inconscientes, mas especialmente destes últimos, a fim de podermos avaliar com mais clareza algumas dificuldades que esta teoria enfrenta e quais teses ela deveria melhor esclarecer.

\section{O problema do estatuto ontológico}

Searle defende que uma das vantagens de sua teoria da intencionalidade em relação à tradição é poder explicar o problema do estatuto ontológico dos objetos intencionais. Em sua visão, esta questão pressupõe uma 
noção errônea de intencionalidade, visto que se procura algo correspondente para a noção de intenção, mas a intenção é apenas uma forma de intencionalidade entre outras. Além disso, deve-se fazer a distinção entre conteúdo de uma crença e objeto de uma crença. Tomemos aqui o exemplo do próprio autor: um indivíduo $\mathrm{x}$ acredita que $\mathrm{o}$ rei da França é careca. Neste caso, x possui uma crença que possui um conteúdo proposicional com determinadas condições de satisfação. Porém, como não há um objeto no mundo que seja o rei da França, então a crença deste indivíduo não pode ser satisfeita. Em suas palavras:

The fact that our statements may fail to be true because of reference failure no longer inclines us to suppose that we must erect a Meinongian entity for such statements to be about. We realize that they have a propositional content which nothing satisfies, and in that sense they are not "about" anything. But in exactly the same way I am suggesting that the fact that our Intentional states may fail to be satisfied because there is not object referred to by their content should no longer puzzle us to the point where we feel inclined to erect an intermediate Meinongian entity or Intentional object for them to be about. An Intentional state has a representative content, but it is not about or directed at its representative contents. (SEARLE, 1983: 17)

Isto significa que o fato de um objeto intencional não existir no mundo não nos obriga a admitir a existência de uma entidade intermediária para a qual a crença de $\mathrm{x}$ é dirigida. Contudo, é possível que se argumente dizendo que, do ponto de vista fenomenológico, a crença de x é sobre o rei da França e que nós temos um objeto intencional com um tipo de existência. A solução apontada por Searle para o estatuto ontológico dos objetos intencionais quando eles não existem é que a expressão "acerca de" pode ser interpretada de duas formas: (i) no sentido intensional e (ii) no sentido extensional. No primeiro sentido, a crença ou o enunciado de que é rei da França é careca é sobre o rei da França. No entanto, isto não significa dizer que existe um objeto no mundo que seja o rei da França e o indivíduo x acredita que ele é careca, mas que existe um conteúdo proposicional. No segundo sentido, não há qualquer objeto que seja o rei da França. O modo como este autor tenta dissolver o problema ontológico dos objetos intencionais parece ser inicialmente claro e muito simples, mas esta proposta de solução não consegue responder a seguinte questão:

(a)Qual é o estatuto ontológico dos conteúdos proposicionais de nossos estados intencionais?

No âmbito de sua teoria da linguagem, Searle afirma que concorda com Gottlob Frege (1848-1925) que uma expressão se refere a um objeto porque o objeto satisfaz o Sinn [sentido] associado para a expressão. Contudo, ele não aceita a existência de um terceiro reino com entidades abstratas tais como sentido, conteúdos proposicionais etc. (SEARLE, 1983: 197). Mesmo assim, a questão acima faz sentido, pois nos casos dos estados inconscientes, o estatuto ontológico destes estados mentais parece inicialmente não ser claro, pois em sua obra Intencionalidade (1983), ele considera a memória como um recipiente cheio de pensamentos que existem apesar de não serem atuais ou mesmo que a pessoa nunca sequer tenha pensado conscientemente sobre isto. Para ter um determinado pensamento p, basta que o sujeito se comporte como se tivesse este pensamento. Além disso, como já foi dito, os estados 
intencionais atuais de um indivíduo só funcionam devido a uma rede [network] de outros estados intencionais e um conjunto de capacidades que ele denomina background. A maioria destes estados intencionais é inconsciente. Por exemplo, se uma pessoa deseja se candidatar ao cargo de presidente do Brasil, ele só pode ter este desejo porque ele possui um conjunto de outros estados mentais e capacidades do background que possibilita este indivíduo ter esta intenção. As capacidades do background não podem ser consideradas como outros estados intencionais. Mesmo assim, este indivíduo não poderia ter esta intenção se ele também não acreditasse que existe um país chamado Brasil, que este país possui um sistema eleitoral, que ele tem o direito de ser um candidato etc.

A rede de pensamentos ou crenças com um conteúdo proposicional pressuposta por este indivíduo ao vivenciar um estado intencional complexo como este parece ser enorme. O problema do estatuto ontológico destes pensamentos não atuais, os quais fazem parte da rede do indivíduo, não é tratado claramente em seu livro Intentionality, mas a partir de sua obra The Rediscovery of the Mind (1992), Searle parece tentar resolver este problema quando ele afirma que a memória não pode ser considerada como um recipiente de pensamentos e imagens e que a mente não é um conjunto de estados mentais, alguns conscientes e outros inconscientes. Estas visões erradas derivam da gramática de nossa linguagem e de nossa cultura. A memória passa então a ser vista como uma capacidade do background de produzir estados mentais conscientes e a mente deixa de ser um inventário de estados mentais conscientes e inconscientes. Isto significa que, conforme sua nova posição, os estados mentais inconscientes fazem parte do background.

Além disso, ele passa a afirmar que apenas os estados conscientes ou estados mentais atuais possuem uma realidade psicológica. No âmbito da neurologia, os estados inconscientes ou pré-conscientes não possuem um conteúdo intencional e um aspecto em si. Em outras palavras: Os estados mentais inconscientes só possuem uma intencionalidade de forma potente. $\mathrm{O}$ conteúdo proposicional e a forma aspectual dos estados inconscientes surgem apenas quando estes eventos mentais emergem em nossa consciência. Como isto exatamente funciona, ele não explica. Outra questão que surge neste contexto é:

(b) Os estados mentais inconscientes têm uma subjetividade ou uma ontologia de primeira pessoa?

Esta pergunta faz sentido na medida em que, conforme Searle, estes estados mentais não possuem uma realidade psicológica e como nós vimos anteriormente, para a sua existência, eles devem ser experenciados por alguém. A resposta de Searle para esta questão é:

The ontology of the unconscious intentionality consists entirely of thirdperson, objective, neurophysiological phenomena, but all the same the states have an aspectual shape that cannot be constituted by such facts, because there is no aspectual shape at the level of neurons and synapses .(SEARLE, 1992: 159)

Sendo assim, os estados mentais inconscientes que temos são apenas eventos neurobiológicos capazes de gerar consciência e intencionalidade e possuem uma ontologia de terceira pessoa. Dito de outro modo: A única ontologia que existe nestas formas de inconsciente é uma neurofisiologia capaz de gerar estados conscientes e comportamento consciente. Apenas quando eles surgem para a consciência, isto é, deixam de serem inconscientes, os estados mentais passam a 
ter uma ontologia de primeira pessoa. Isto nos leva para a próxima questão:

(c) $\mathrm{O}$ que torna um estado inconsciente mental?

Conforme Searle, os estados inconscientes são intrinsecamente mentais. Alguns processos que ocorrem na mente são inconscientes e outros conscientes. Entre aqueles que são inconscientes, existem processos neurofisiológicos que são mentais, pois eles são candidatos à consciência, ou seja, eles são capazes de gerar estados conscientes. O que significa também dizer que eles são pré-conscientes e pré-intencionais. Deste modo, é em virtude da capacidade de gerar estados conscientes, isto é, de serem disposições, que os estados inconscientes são mentais. Neste contexto, surge então mais uma questão:

(d) Como a rede de estados inconscientes pode determinar as condições de satisfação dos estados intencionais conscientes, como, por exemplo, a intenção de se candidatar a presidência da república de um indivíduo qualquer?

Segundo Searle, a rede não é suficiente para a determinação das condições de satisfação dos estados intencionais, pois ela necessita do background. No entanto, a rede faz parte do background e não seria um conjunto de estados intencionais com proposições completas e formas aspectuais. Entre as diversas capacidades do background, ou pano de fundo, estão as capacidades de produzir estados conscientes intencionais, as quais constituem a rede. Por exemplo, nós podemos afirmar de vários brasileiros que eles acreditam que a capital do Brasil é Brasília quando eles estão dormindo. Ao contrário de sua concepção anterior, Searle passa afirmar que nós podemos fazer este tipo de afirmação não porque eles teriam um conjunto de estados intencionais inconscientes com conteúdos proposicionais e formas aspectuais, mas porque estaríamos descrevendo algumas capacidades de background que estes indivíduos possuem ao pensar que a capital do Brasil é Brasília.

Deste modo, estas capacidades de background têm intencionalidade e consciência latente. $\mathrm{O}$ conteúdo proposicional do pensamento não atual de que a capital do Brasil é Brasília seria apenas um conteúdo intencional possivel com uma forma aspectual possivel. Vale observar que mesmo assim, em sua visão, os estados inconscientes são intencionais não em um sentido metafórico, mas no sentido literal (SEARLE, 1992: 156). Esta afirmação é coerente com sua tese de que a intencionalidade, seja ela latente ou atual, é sempre intrínseca, mas Searle deverá apresentar agora outro exemplo que confirme sua tese de que nem todos os estados intencionais são estados conscientes, pois sendo os pensamentos não atuais préintencionais e pré-conscientes, eles não podem ser mais vistos como casos de estados mentais que são intencionais, mas não são conscientes.

\section{Considerações finais}

Em suma, a separação entre consciência e intencionalidade feita na teoria searleana da mente passa a ser questionável a partir do momento em que ele precisa lidar com o problema do estatuto ontológico do conteúdo proposicional dos estados inconscientes e da memória. Searle reconhece algumas dificuldades que sua teoria da intencionalidade apresentada em Intentionality (1983) enfrenta e desenvolve suas noções de memória e de mente passando a tratar a memória como parte do pano de fundo ou background e a mente como uma espécie de inventário de estados 
mentais. Com esta mudança, os estados inconscientes são tratados como parte do background, isto é, como disposições do cérebro capazes de gerar estados conscientes intencionais. Contudo, esta nova posição levanta a questão se é possível haver mesmo estados intencionais sem a consciência no sentido apresentado inicialmente pelo mesmo, visto que ele não consegue mais fornecer um exemplo de estados mentais que seja intencional, mas não seja consciente. Por este motivo, em minha opinião, Searle deveria alterar também sua tese inicial acerca da relação entre consciência e intencionalidade para ser coerente com suas novas teses e definições apresentadas em sua filosofia da mente afirmando simplesmente que todo estado intencional é consciente. Neste sentido, para Searle, a consciência e não a intencionalidade é a propriedade fundamental da mente. Esta é uma tese que ele deverá continuar defendendo com melhores argumentos, visto que existem contraargumentos consideráveis oferecidos por filósofos analíticos tais como Crane e Tye.

Além disso, as distinções entre potencial e atual e realidade neurofisiológica e realidade psicológica parecem ser descritas para tentar explicar uma surpreendente combinação entre a objetividade ou ontologia de terceira pessoa do inconsciente e seus possíveis conteúdos mentais com modos aspectuais latentes, os quais ao surgirem para a consciência tornam-se atuais e de repente adquirem propriedades irredutiveis tais como a subjetividade ou ontologia de primeira pessoa. Esta abordagem do inconsciente soa estranha, pois Searle não pretende fornecer uma abordagem fenomenológica da mente e ela nos lembra do dualismo de propriedades que ele mesmo rejeita ao admitir a existência de uma dicotomia de propriedades e realidades no âmbito do mental. Deste modo, a explicação de que uma parte do nosso background possui uma realidade neurofisiológica mais do que psicológica e se manifesta através de pensamentos conscientes com uma realidade psicológica com propriedades subjetivas e irredutíveis a uma perspectiva de terceira pessoa parece ser análoga a um coelho que sai de repente de uma cartola e, portanto precisa ainda de mais esclarecimentos.

\section{Referências Bibliográficas}

BRENTANO, Franz. Psychologie vom empirischen Standpunkte (1874). Von der Klassifikation der psychischen Pbänomene (1982). Band 1. Frankfuhrt: Ontos Verlag, 2008.

CARVALHO, M. Joelma. Intentionalitätstheorie beim frühen Brentano und bei Searle. München: Philosophia Verlag, 2013.

CRANE, Tim. Elements of mind. Oxford: Oxford University, 2001.

Intentionalität als Merkmal des Geistigen. Sechs Essays zur Philosophie des Geistes. Tradução de Simone Ungerer e Markus Wild. Frankfurt: Fischer Taschenbuch Verlag, 2007.

DENNET, Daniel. C. Consciousness Explained. London: Penguin Books, 1991.

DRETSKE, Fred. Naturalizing the Mind. Mass: MIT Press, 1994.

KEMMERLING, Andreas.Von der Sprache zum Bewusstsein: John R. Searle löst sich vom analytischen Mainstream. In: Merkur - deutsche Zeitschrift für europäisches Denken. 48, 5. pp. 432-8, 1994.

MEIJERS, Anthonie. W. M.. Mental Causation and Searle's Impossible Conception of Unconscious Intentionality. In: International 
Journal of Philosophical Studies. Vol. 8(2), pp. 155-170, 2000.

MONTAGUE, Michelle. Recent Works on Intentionality. In: Anabsisis Vol. 70, No. 4, outubro, pp.765-782, 2010.

SEARLE, John. Consciouness, Unconsciouness, and Intentionality. In: Philosophical Topics. Volume XVII. Nº. 1. pp. 193-209, 1989.

Geist. Eine Einfübrung. Tradução de Sibylle Salewski. Frankfurt: Suhrkamp, 2004.

Intentionality. An Essay in the Philosophy of Mind. Cambridge: Cambridge University Press, 1983.

Minds, Brains and Science.

The 1984 Reith Lectures. London: British Broadcasting Corporation, 1984.

Mind, Language and Society.Philosophy in the real world. New York: Basic Books, 1997.

. The Mystery of Counsciousness. London: Granta Books, 1997.

. Theory of mind and Darwin's Legacy. In: National Academy of Sciences. In the Light of Evolution VII: The Human Mental Machinery. Vol. 110. pp. 10.343-10.348, 2013.

The Rediscovery of the Mind. Mass: Massachusets Institute of Technology, 1992.

TYE, Michael. Ten Problems of Consciousness. A Representational Theory of the Phenomenal Mind. Mass: MIT Press, 1996.

Revista de Filosofia Moderna e Contemporânea

Brasília, vol 4, no 2, 2016. 